\title{
ABOUT THE BENEFITS OF THE CRISIS-PHENOMENOLOGY INSPIRED BY BERTALANFFY
}

\author{
Author(s) / Auteur(s) : \\ Istvan BAJZAK \\ Independent philosopher \\ Bajzak Consulting \\ info@bajzak.com
}

\begin{abstract}
Résumé :
Bertalanffy defined a science-philosophical research program. In the light of this illumination I will present the most inspirational crisis concept. True science avoids the dualism. By doing so, it will not be a set of objective facts that must be accepted with authority - but a phenomenological observer's inspiration inspiring individual thinking. Such an analysis of the crisis is also an action program, and it also gives us communication theory and a new ethics. What does not require the prior election, that Bertalanffy has had with strong criticism with. This approach leads to the mental generosity shown by Ervin László in an interview. This is a true integral view, where the content of the mind and the optimum result expected from the hermeneutical structure that interpret it are not contradicted, meaning that the intellect does not resemble unity, intelligence-centred communication theory and ethics. The source code theory. The descriptive ability of Varela's phenomenological observation is the first step towards the solution.
\end{abstract}

\section{Keywords / Mots-clés :}

crisis, integrated information theory, body-mind problem, sourcecode theory, communication theory

\section{STARTING POINT}

When I create a situation in which I read or talk or listen to lectures, I am confronted by questions like climate change, global warming, globalisation, international or private conflicts, illnesses, finding solutions and sustainability, etc.. Then I focus on these. Finding more and more information, weighing and recognising the severity of the problem. To change my world, I seek and communicate with partners to improve and resolve the situation.

Now all this process is approached by Bertalanffy's program of science philosophy (3).

From this research emerges a new philosophy of science, communication theory and ethics (but also religion philosophy, theology). It dissolves the opposition and intimidation between overseas and continental attitudes.

In addition, it presents a crisis management strategy for me, the implementation of which is more difficult and simpler because it only depends on me. Perhaps because accepting responsibility for crisis-consciousness and solving is solely my business.

\section{GENERAL CHARACTERISTICS OF CRISIS}

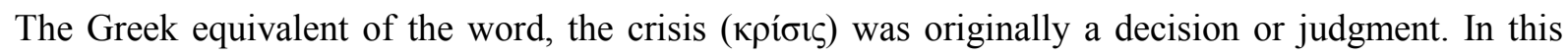
original report, everything is already there.

Where does a crisis come from, how does the crisis develop in me (be it workplace or partnership conflict, personal or societal, cultural or financial, etc.)?

I'm sure I can see it in text: I read, hear about it, or compare my recent experiences with the thought of an assumed former fact's memorial abstraction, and then I find that the set of data and information I know causes unrest and disharmony in me. Do more types of crises exist? Are there any common features in the emergence of crises on which to set up a common crisis model to synthesize a variety of categories? In the emergence of crises, the information aspect can be identified as a common 
feature, as one common crisis model. The common characteristic of crises is that I can see all crises as information crises. I focus on the data (fragments) I choose from the information surrounding me. In these data I look for and find causal relationships and then interpret them, at present, just as one describes a crisis, manifested in some form. Why and how is this crisis an information crisis?

This is an information crisis because there is disharmony between data and their interpretation, which are the contents of my mind - unprocessed, refused or denied. I don't want to acknowledge something, something has no organic place in the world or in the picture I have of the world.

Where appropriate, the possibility and probability of the extinction of human civilisation will not be allowed in my world. According to Hoffmann's text, one who is able to see everything, is extinct, and who is more able to adapt, survives. Even if he does not see the point. This is "evolution." But consciousness can also develop, consciousness can be surviving.

However, by his nature, because of the lack of the overwhelming need of life, it is not in the race but in the individual. Taking the individual's full responsibility is the path to the development of intelligence. (see Ramachadran, Hoffner, Luhmann)

I meet the text and unconsciously translate into my mind, my mind is the horizon for processing data and solving the problem. The anthropocentrism is that "(some) people are a global crisis factor". (Charles François)

\section{PRE-CHOICE IS A RESULT OF DUALISM}

In the description, interpretation and presentation of every scientific result, I can find a concealed, original, perhaps unconscious, choice.

By this choice, it is shown to me that, in terms of the specific description, and in general, the text itself derives knowledge from itself.

It also shows in what horizon the source of the text wants (with the reader of the text) to see the elements presented in it, and the causal relation to each other and to the outside of the text.

The text still causes me, in its acquaintance, the implicit, unexplained knowledge of how much and what kind of essence of needs of being I have, imagining the elements discussed in the text.

(Train / icon, train viewers / icon ?, see Hoffmann) Of course, the text to be processed can be generated in unwritten form, so I just hear it as a lecture. The pre-(unconscious or pre-conscious) choice is the choice of a certain way of responding. This is the answer to the question of the duality of where I derive the knowledge. Actually, this is an ancient big task, in a little different form:

"Get to know yourself!"

To comply with the "Bertalanffy Program" during my information processing, I need to break these transparent layers. Since neither source are well-founded (body or mind) scientifically already in existence, so when I want to get myself information, I have to break out the pure information from the human (literary, scientific, everyday, etc.) form of information.

To this end, there has not yet been a system that is scientific, teachable and properly open to infinite expansion.

\section{THE NEW VISION}

The new approach is a comprehensive system. The new system that satisfies the needs is the source code theory. The source code theory is an elegant copernicus turn of current system approaches (integral approach, IIT, etc.).

This view is therefore the most authoritative descriptive approach. If I want to be an undisputed observer, then science does not result in compelling facts, but merely inspires thought and action. If I accept, by virtue of authority or any other principle, reading a sense of reading or listening to a consciousness that is objective and real, then I answer the question of dualism. 
The Source Code theory does not bring anything new to me, but the courage to use knowledge, so any data that may appear or appear in my mind will be able to be treated without denying or discrediting myself.

By doing so, the Bohm dialogue does not even interfere with a dialogue group. Regardless of the size and complexity of the group.

\section{This is a true integral approach.}

There is nothing else to do, but I have to make every statement, experiential description, thought, and thought so that dualism does not run out.

The base: to say yes to being, being-yes, the affirmation of the continuous, unrestricted opportunity of my experience, an attitude that allows and resolves anything that can be processed in my mind that comes into it. No matter what the source of new information. Once I have focused my attention on it, I have to say yes to it. I will be able to do this by the source code theory.

The data surrounding me, which through my experienced iris (now probably filtered) become the raw material of my conscious focus, my own, almost free-willed individual choice is placed in the focus of my attention. My mind interprets its own content and makes some evaluation: bad or good. In me, in the observer, I felt some sense. In order to survive, I need to make the feeling positive. Or argue, I can search for truth, or refer to authority, or in any other way. But the biggest positive feeling is when I am expanding my imagination and interpreting incoming data with a system that will enable me to interpret positively any new information and the opposite.

This part of source code theory, about internal communication, about creating identity. (see Luhmann) I will be able to communicate in such a way that I can reach the greatest possible positive interpretation and agreement on the widest possible horizon (eg with the Planetary Approach, see Ervin László's Planetary Ethics).

The source code theory brings me back to the original state and moment of creation of things as they are created. Whatever interpretation I choose, either the Descartes doubts or the traceability (see Varela), in every way I find out what that is what it is? (see Quine)

\section{CRISIS MANAGEMENT SCIENTIFIC}

So crisis is the experience of the tension between the understanding of the information / data that comes to my mind and the idea of the expected optimum situation.

When I want to solve a problem, I need to communicate. All my communication begins with the choice of form, style, I define the communicating Self, I will be present in communication through this Self. Consciously or unconsciously, it does not matter, but it happens in advance. (Luhmann)

My definite self brings with it the structure that will lead me to the "experience of things". I communicate my roles and communicate through them (philosopher, scholar, priest, father, man, white-skinned, religious etc.) By my communication - like the bat through echolocation - I create the "reality" around me about reactions, feedbacks . Reactions cause feelings within me, these feelings are the only certainty to me about the world. All of them are defined by Me for me. My original, basic attitude to myself, to the thought of myself while experiencing.

The crisis turned out to be the conflict of my own internal communication. My interpretation is ineffective, it denys the unity of the data and my interpretative structure in my mind. Unprocessed information is once again manifested, materialized.

The biggest illusion is that all that appears in my "mind" is attributed to the same ontological status as the ontological status of the site of the appearance. This approach to the source code approach will be the subject of my next paper.

So I get to Ervin László's conclusion in an interview: "The infinite intelligence (Infinite Creative Intelligence) does not matter in what form it recognizes and recognizes itself in itself, if it is not human, it is infinite intelligence. And man does his best to destroy himself as a potential intelligence supporter. "(The content of the citation is accurate, not literal.) 
How can I handle the crisis if I do not want to be just an adaptable survivor?

Spread my horizons of imagination appropriately, with the widest possible community attitudes.

I have to answer it after I get into a certain situation where "What do I want to experience?" "How can I get the most information $I$ have in that situation? How can I get the most pleasure from the situation?" Accordingly, I have to act and communicate in the next moment. The new moment is not a consequence of the past, but depends only on the answers to these questions. The size of my responsibility for my condition and the degree of my creative freedom are directly proportional.

If I think of a system that is not open to a completely different way of thinking (knowing that it is no more justified to think in such a way than otherwise), its affirmation, the recognition of its eligibility than what I need for my own mentality, that is, if I think in a limited openness system, then the maximum degree of Phi's $(\phi)$ reach (see Tononi's IIT) will be limited, my intelligence can not be manifest in the given situation because of my pre-set constraints. If I use this crisis strategy, then my intelligence (real-looking) will not live longer, but only the leaked intelligence-carrying form that is well suited to the crisis. (see Hoffman)

My search for objections in order not to take responsibility, to maintain my limitations, always tells me that I insist on some non-scientific illusion. My mind does not give me anything to make a dissonance. My own choices and my own focus had preceded all my moments. If such a feeling is felt in me, then I have to look at the current information decoding hermeneutical structure. Whether involuntarily, unconsciously or deliberately, but only I use it and use it, it is not the same as me.

What kind of structure do I consider to be the whole system? Can system-level problem management be resolved without prior selection? What can I say about my experiences of constructivism? If I argue with them, I argue with my own content, Hoffmann and Chalmers's own "stats". If I want to wrest the truth, then with the content of my mind (forgetting that time and causation in the given situation are just my mind to interpret the information) I want to win. Absurd.

How to go on?

I choose my interpretation method myself. In my choice, there is a horizon. Within this horizon I perceive the situation. I believe that this horizon must be resolved and within that it is possible to resolve the crisis. By dealing with the crisis I actually do my job: Know yourself. Unnecessary attachments are overwhelming and I get to science based on the fact that I'm just a variation of the self-reflection of infinite creative intelligence.

Determining the cause-and-effect relationships also shows me how wide the horizon of my interpretation and imagination, within which I searched the relationships and the solutions, how far I expanded.

All the information I have at my disposal is to create a next day that is unbroken in which my relationship with myself is harmonious and, accordingly, undertake my complete creative responsibility, with my greatest freedom, to shape my world and my future.

Without fear of death. 


\section{RÉFÉRENCES}

Bertalanffy, L. (1969). Robots, Men and Minds. NY, George Braziller, 94.

"It should be apparent by now that the mind-body problem has proved to be insoluble in the ways of traditional philosophy. The centuries-old debate was little more than a mutual refutation of the classical theories of interaction, parallelism, identity, epiphenomenalism, etc- each one demonstrated, in convincing arguments, to be untenable. But may it not be that the mind-body problem was created by wrong categorizations? In one way or the other, and with whatever minor modifications, all theories took for granted the Cartesian dualism of matter and mind, thins and consciousness, object and subject, res extensa and res cogitans; accepting them as indubitably given and trying to bring them into some intelligible relationship. By now, however, it has become obvious that neither "matter" nor "mind" stood up to the test of scientific investigation. Cartesian matter has "dematerialized" in physics-see Einstein's equation and atomic explosions. And mind, originally concived as consciousness, has become no less problematic since the exploration of the unconscious, of which consciousness is only a minor, and possibly not the decisive fraction.

Bohm, D. (1957). Causality and Chance in Modern Physics. University of Pennsylvania Press, 1-35.

Chalmers, D. (2010). "Facing Up to the Problem of Consciousness". The Character of Consciousness. Oxford University, I/1.

Eco, U. (2000). "Ethics are Born in the Presence of the Other". Belief Or Nonbelief. Arcade Publishing, NY, 80-89.

Hoffman, D. D. (2008). "Conscious Realism and the Mind-Body Problem”. Mind \& Matter Vol. Imprint Academic, 6(1):87-121.

Luhmann, N. (1990). "Identitäte - was oder wie?". Soziologische Aufklärung 5. Opladen, Westdeutscher Verlag,:14-30.

Putnam, H. (1981). "Brains in a vat". Reason, Truth and History. . Cambridge, UP, 1-22.

Quine, W.O. (1961) “On What There is". From a Logical Point of View, $2^{\text {nd }}$ ed. Harvard University Press,

Ramachadran, V. (2009). The neurons that shaped civilization. TED India, http://www.ted.com/talks/vs_ramachandran_the_neurons_that_shaped_civilization.html

Rizzolatti, G. \& Craighero, L. (2004). "The Mirror-Neuron System”. Annu. Rev. Neurosci. 27: 16992.

Roediger, H. L. \& Karpicke, J. D. (2008). "The Critical Importance of Retrieval for Learning ". Science, Vol. 319:966-968.

Tononi, G. (2016). "Integrated information theory: from consciousness to its physical substrate". Nature Reviews Neuroscience 17:164-054.

Searle, J. (1980). “Chinese Room argument”. Behavioral and Brain Sciences, 3: 417-57.

Stonier, T. (1990). Information and the Internal Structure of the Universe. Springer-Verlag London, Varela, F. (1997). "Neurophenomenology". Explaining Consciousness: The Hard Problem. MIT Press, Cambridge, 337-357. 
